\title{
A Mass-Selective Variable-Temperature Drift Tube Ion Mobility-Mass Spectrometer for Temperature Dependent Ion Mobility Studies
}

\author{
Jody C. May, David H. Russell \\ Department of Chemistry, Texas A\&M University, College Station, TX, USA
}

\begin{abstract}
A hybrid ion mobility-mass spectrometer (IM-MS) incorporating a variable-temperature $(80$ $400 \mathrm{~K}$ ) drift tube is presented. The instrument utilizes an electron ionization (EI) source for fundamental small molecule studies. Ions are transferred to the IM-MS analyzer stages through a quadrupole, which can operate in either broad transmission or mass-selective mode. Ion beam modulation for the ion mobility experiment is accomplished by an electronic shutter gate. The variable-temperature ion mobility spectrometer consists of a $30.2 \mathrm{~cm}$ uniform field drift tube enclosed within a thermal envelope. Subambient temperatures down to $80 \mathrm{~K}$ are achievable through cryogenic cooling with liquid nitrogen, while elevated temperatures can be accessed through resistive heating of the envelope. Mobility separated ions are mass analyzed by an orthogonal time-of-flight (TOF) mass spectrometer. This report describes the technological considerations for operating the instrument at variable temperature, and preliminary results are presented for IM-MS analysis of several small mass ions. Specifically, mobility separations of benzene fragment ions generated by El are used to illustrate significantly improved (greater than $50 \%$ ) ion mobility resolution at low temperatures resulting from decreased diffusional broadening. Preliminary results on the separation of long-lived electronic states of $\mathrm{Ti}^{+}$formed by El of $\mathrm{TiCl}_{4}$ and hydration reactions of $\mathrm{Ti}^{+}$with residual water are presented.
\end{abstract}

Key words: Ion mobility-mass spectrometry, Cryogenic drift tube, Electron ionization, MS-IM-MS, Isomeric separations, Metal electronic states

\section{Introduction}

$\mathrm{H}$ ybrid ion mobility-mass spectrometers (IM-MS) based on drift tubes coupled to orthogonal time-of-flight mass spectrometers (TOF) were first introduced over 40 y ago [1, 2]; however, the analytical utility of these types of instruments was not fully realized for several decades. A resurgence of interest in the IM-MS technique evolved from work by Bowers and coworkers [3] and Jarrold [4, 5], and

Electronic supplementary material The online version of this article (doi:10.1007/s13361-011-0148-2) contains supplementary material, which is available to authorized users.

Correspondence to: David H. Russell; e-mail: russell@chem.tamu.edu by Clemmer and Jarrold [6]. The renewed interest coincided with technological advances afforded by the analytical refinement of orthogonal TOF instruments [7], efficient transfer of ions from high pressure ion sources to vacuum [8], the development of low-pressure (less than 10 Torr) drift tube designs, which are more easily adapted to high vacuum mass spectrometers and ionization techniques capable of forming intact biomolecular ions. In addition, elevated pressure ion focusing strategies such as electrostatic ion guides [9] or electrodynamic rf fields [10-12] have greatly improved the ion transmission of the ion mobility spectrometer, and the recently introduced traveling-wave ion mobility instrument utilizing high resolution orthogonal TOF mass analysis has enormous potential for a broad range of studies from small molecules to macromolecules, includ- 
ing MDa protein complexes [13]. Despite the development of these novel IM technologies, the traditional uniform field drift tube IM continues to provide the most reliable determinations of ion-neutral collision cross sections and performs with the highest achievable ion mobility resolving powers $[14,15]$.

Variable temperature ion mobility experiments were first explored a century ago by Phillips [16], Kovarik [17], and Erikson [18], and the precision of these experiments were later improved by the work of Tyndall and coworkers [19, 20]. The first temperature-controlled drift tubes coupled to mass spectrometers emerged in the 1960s from several groups and were used in fundamental studies of ion transport and ion reaction chemistry mass-resolved over a wide range of temperatures [21]. Mass selection prior to IM-MS analysis was utilized by McDaniel and coworkers, and Hasted and Bloomfield, as a means of elucidating the complex ion chemistry, which can occur for atomic and small molecular ions $[22,23]$. This work directly influenced the development of mass-selected flow [24] and drift tube reactors [25]. In the early 1990s, the groups of Bowers and Jarrold both developed several novel low-temperature drift tube IM-MS instruments in their pioneering studies of atomic clusters [26, 27] and transition metal ions [28]. Experimental measurements of ion-neutral interaction potentials and collision cross-sections and widely accepted theoretical methods useful for extracting structural information from the IM measurement have resulted largely from these studies [29-31]. Additionally, many of these instrument designs were later modified for the study of biological ions in the gas phase, and provide us with much of our current body of data on anhydrous peptide and protein conformational thermodynamics $[32,33]$. For low temperature operation, these instruments utilized liquid nitrogen, though there are at least a few examples of liquid helium drift tubes being developed for the study of ion-molecule interactions at very low energies [34-36]. These examples underscore the fundamental importance of variable temperature drift tube measurements.

The drift tube IM experiment is a time-of-flight measurement of the migration of a finite pulse of ions as it traverses from one end of a gas-filled region to the other [21]. Ion motion is directed by means of an electric field applied across the drift region. Measured ion arrival times are averaged over several IM experimental cycles, yielding a distribution of the average ion arrival time. The characteristic ion mobility parameter, $K$, is a measure of the average drift velocity, $v_{d}$, over the applied electric field, $E$ :

$$
K=\frac{v_{d}}{E}
$$

The values of $v_{d}$ and $E$ can be ascertained directly from the measured average ion arrival time and known drift potential and length of the drift region. The linear proportionality of $K$ with the measured drift time is maintained so long as $E$ is kept relatively small (so called low-field conditions). In order to compare mobility measurements across different instrument platforms, the measure mobility value can be corrected to standard gas density using the relationship [21]:

$$
K_{0}=K \frac{273.15}{T} \frac{P}{760}
$$

Where $K_{0}$ is referred to as the reduced mobility and $P$ and $T$ are the pressure and temperature of the drift gas during the measurement.

Recent work by Hill and coworkers using various drift gas compositions underscored the utility of altering the iongas interaction to change the relative value of $K$ and enhance the IM separation $[37,38]$. Early variable temperature drift tube work has also validated the significant effect of the gas temperature on changing the gas-phase ion mobility, particularly to longer drift times [18, 39], though the extent of the temperature on the analytical IM separation has not yet been investigated in extensive detail. While both high and low temperature drift gas experiments can affect the separation of ions in the drift tube experiment [40-43], there is practical utility in conducting the separation at low temperature since a significant cause of band broadening, thermal diffusion, decreases with a decrease in the drift gas temperature. This effect is apparent from the low-field ion mobility resolving power equation [44]:

$$
R=32.33\left(\frac{L E z}{T}\right)^{\frac{1}{2}}
$$

Here $L$ is the drift length, $z$ is the ion charge state and $T$ is the drift gas temperature. Equation 3 also underscores the importance of extended length drift tubes and the use of high voltages on enhancing the resolving power. Other contributing factors to resolving power not accounted for in Eq. 3 include space charge and ion-gas reaction chemistry, though these effects can be minimized with proper experimental techniques (e.g., temporally narrow ion pulses and high purity gases, respectively).

In this work, we describe a mass-selectable ion mobilitymass spectrometer (MS-IM-MS) with variable temperature drift tube capabilities. While one underlying motivation of variable temperature ion mobility work is to improve the IM separation efficiency, there are a number of other applications of this type of instrumentation, including fundamental studies of ion-neutral interactions. In the following sections we describe the instrument in detail and provide some preliminary characterization experiments alongside examples of application.

\section{Experimental}

Figure 1 contains a schematic representation of the variable temperature ion mobility-mass spectrometer. The instrument 


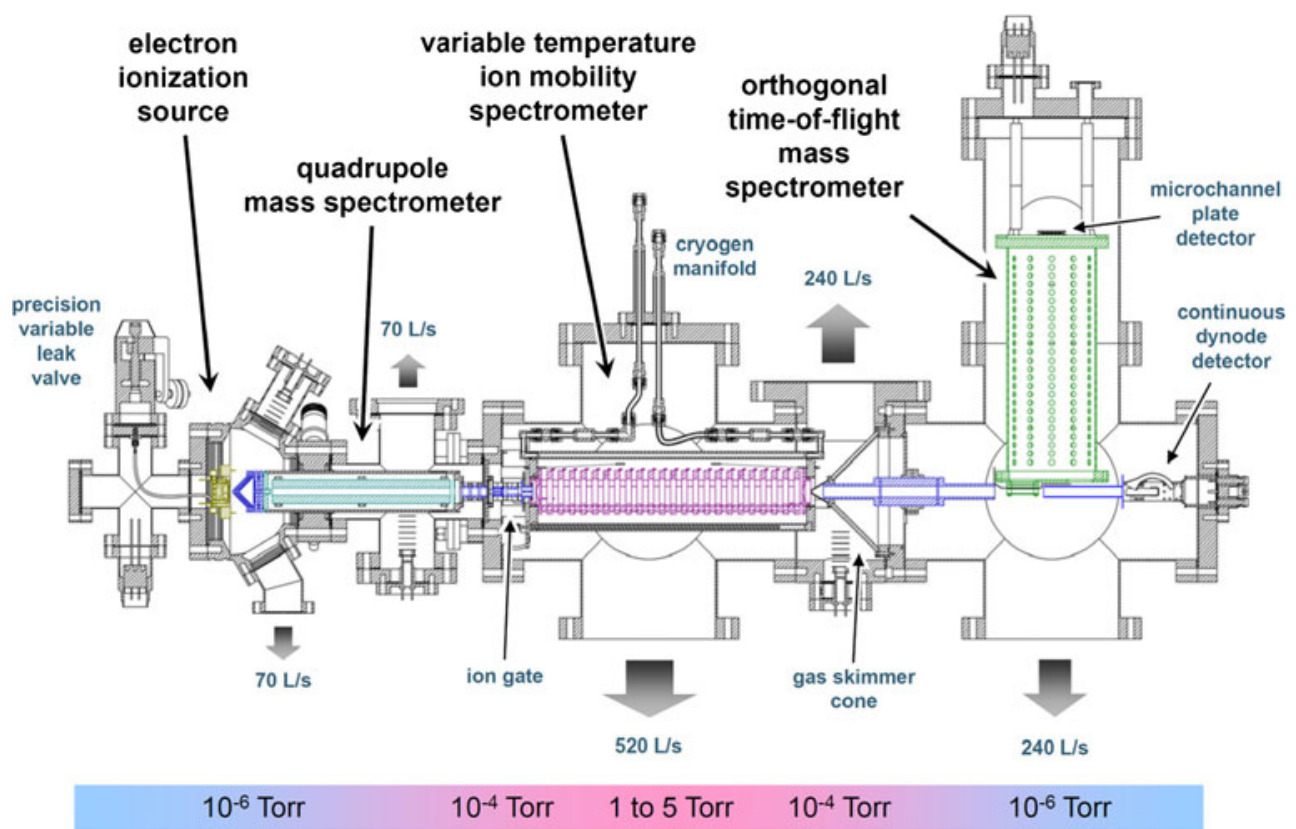

Figure 1. Schematic of the mass selectable, variable temperature drift tube ion mobility-mass spectrometer. Instrument component labels and relevant vacuum system details are provided

is comprised of an electron ionization source, a quadrupole mass analyzer, a variable-temperature, uniform field drift tube, and an orthogonal, linear TOF mass analyzer. What follows is a detailed description of each of the major instrumentation components.

\section{Ion Source and Source Ion Optics}

The electron ionization source utilized in this work was recovered from a sector MS (AEI MS9/50; Kratos Analytical, Manchester, UK) and modified with appropriate gas and electrical feed-throughs and mounting hardware in order to incorporate it into the instrumentation described here. The EI source is a closed volume Nier-type geometry, which is capable of generating an electron beam with an energy resolution of $\pm 2 \mathrm{eV}$ [45]. Electrons are generated from a thermionic emitting tungsten filament (1\% thoriated) and defined into a beam using shaping apertures and permanent magnets. The EI assembly is thermostated with a resistive heating cartridge monitored by a K-type thermocouple. Volatile samples are introduced into the ion source through a precision leak valve where the sample is ionized by the variable energy electron beam. Ions are drawn out of the EI source through an electric field orthogonal to the electron beam. Typical draw out potentials are between 1 and $10 \mathrm{~V}$.

The ion optics that interface the source with the forward quadrupole is designed to accept ions from a number of different ionization sources. A schematic representation of the source ion optics and first stage mass spectrometer is contained in Figure 2a. Ion trajectories as calculated by the SIMION ion optics simulation package (ver. 8.0; Scientific Instrument Services, Ringoes, NJ) are contained in Figure $2 b$ and c. The source ion optics consists of two electrostatic stages which are effective at collecting and collimating a spatially disperse distribution of low energy ions (Figure 2b). The first stage consists of a set of three cones. The conical shape creates a focusing field between the source plane and first cone to help collect ions into a beam (Figure 2c). The cone shape also serves a practical means of allowing an unobstructed line-of-sight to a sample stage for LDI experiments. The two stages of ion optics comprise a set of Einzel lenses operated with a combined offset potential (an immersion lens assembly). The ion optics may also be operated with no potential but with reduced ion transmission. The ion source ion optics isolates the source vacuum chamber from the first stage mass spectrometer, allowing the source chamber to be operated either in high or low vacuum, depending on the ionization source used.

\section{Quadrupole Mass Analyzer}

Following ionization, the ions are directed into a quadrupole mass filter (Figure 2a), which can be operated as an rf ion guide or in a mass-selective mode. The quadrupole used in this work is legacy technology reclaimed from a commercial instrument (ELQ-400; Extrel, Pittsburgh, PA). The rod set is $200 \mathrm{~mm}$ in length with $9.5 \mathrm{~mm}$ diameter rods and utilizes a dielectric prefilter in its design [46]. A 2.1 MHz oscillator (150-QC Extrel) was utilized for all experiments described here. In most experiments, the quadrupole is operated in $\mathrm{rf}$ only mode for optimal instrument sensitivity. Ions exit the quadrupole and enter a three-element electrostatic lens where they are focused through a conductance limiting aperture (Figure 3b). The conductance limiting plate is located 
(a)

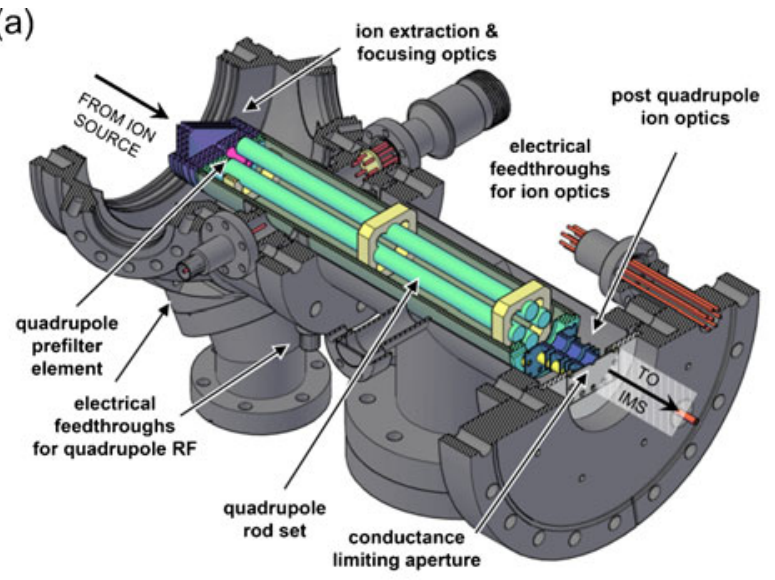

(b)

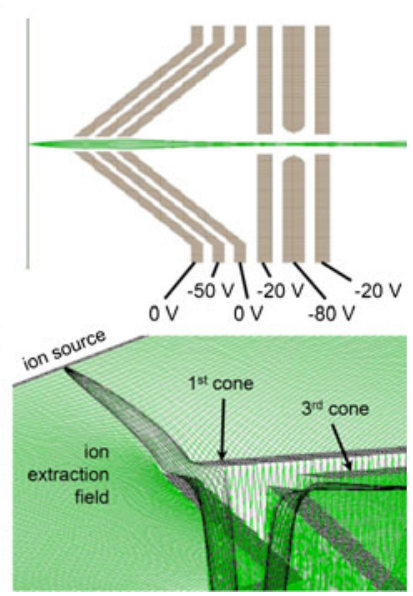

Figure 2. (a) Schematic details of the ion source electrostatics, quadrupole mass analyzer, and associated ion optics. Simulation details of the ion source optics including (b) ion focusing properties and representative potential settings and (c) potential energy surface map illustrating the ion extraction field generated between the source plane and first cone lens

between the quadrupole and IM to define two regions of differential pressure.

\section{Ion Mobility Entrance Ion Optics and Ion Gate Assembly}

The entrance ion optics to the drift tube is comprised of a 3element barrel lens assembly which is designed to decelerate the ion beam prior to injection into the drift region (Figure 3b). Deceleration is accomplished by applying a bias voltage to the cup-shaped electrode defining the entrance to the drift tube. Thus the energies of ions entering the drift region are defined by the potential difference between the ion source repeller electrode and the front electrode of the drift tube. The ion energy is kept low (less than $20 \mathrm{eV}$ ) to minimize ion activation, which can result in endothermic reaction chemistry or ion dissociation (see the Discussion section). The last element of the entrance ion lens is sectioned into quadrants and the voltages applied to each quadrant are independently variable to compensate for mechanical misalignment due to thermal contraction of the drift tube assembly. The sectioned lens creates an effective ion steering optic that can redirect the ion beam in any position within the inscribed radius of the optic. Experimentally, thermally-induced misalignment is observed and manifests as a gradual loss in ion transmission as the drift tube is temperature cycled. Comparable ion transmission is restored with periodic adjustments to the steering ion optic potentials.

A Bradbury-Nielsen style electronic shutter gate [47], consisting of two parallel alternating series of 9 wires each, is located just prior to the entrance to the drift tube. The electronic ion gate can modulate temporally narrow ion pulses (less than $5 \mu \mathrm{s})$ at high $(\mathrm{kHz})$ frequency, which is desirable for generating several low space charge density ion pulses preferable for high resolving power experiments [48]. A gate frequency of $2 \mathrm{kHz}$ corresponds to a mobility temporal window of $500 \mu \mathrm{s}$, which is adequate for the low $\mathrm{m} / \mathrm{z}$ ions investigated under typical operational conditions. A stop potential on the ion gate is applied using equal magnitude, opposite polarity potentials on each of the two wire circuits, which minimizes field penetration effects that perturb ions far removed from the gate. The ion gate pulse is synchronized to the start of the data acquisition, defining time zero of the ion mobility experiment. Pulses are generated using a dual channel high voltage pulser (Ionwerks, Inc., Houston, TX) that operates under computer control. The dual channel pulser generates variable positive and negative potentials that are used for each of the two ion gate wire channels.

\section{Variable Temperature Drift Tube Spectrometer}

The variable temperature drift tube is comprised of a stacked ring electrode design (Figure 3c) consisting of 23 stainless steel rings spaced with ceramic bearings (ca. $8 \mathrm{~mm}$ diameter, grade 25 high alumina nonporous ceramic). A kinematic design is ensured by using three equilaterally spaced ceramic bearings between every drift ring and compressing the assembly with uniform force. The ceramic bearings are captured between every ring electrode $(28.6 \mathrm{~mm}$ i.d., $6.4 \mathrm{~mm}$ thick) by precision bored holes (ca. $4.8 \mathrm{~mm}$ diameter, vented, no chamfer). Rings are electrically connected by a chain of high precision $(0.1 \%) 1 \mathrm{M} \Omega$ metal film resistors (CMF Industrial; Vishay Dale Electronics, Inc., Columbus, NE). The electrodes at the front and back of the ring assembly are machined in a cup-shaped geometry that protrudes outward from the drift chamber on either side. This end electrode cup shape is designed to shield the low energy ions at the entrance and exit of the drift tube from penetrating fields. Commercially available laser drilled aperture disks (Lenox Laser, Glen Arm, MD) are attached to the front and back electrodes of the drift tube using conductive silver epoxy (H2OE Epo-Tek; Ted Pella, Inc., 
(a)

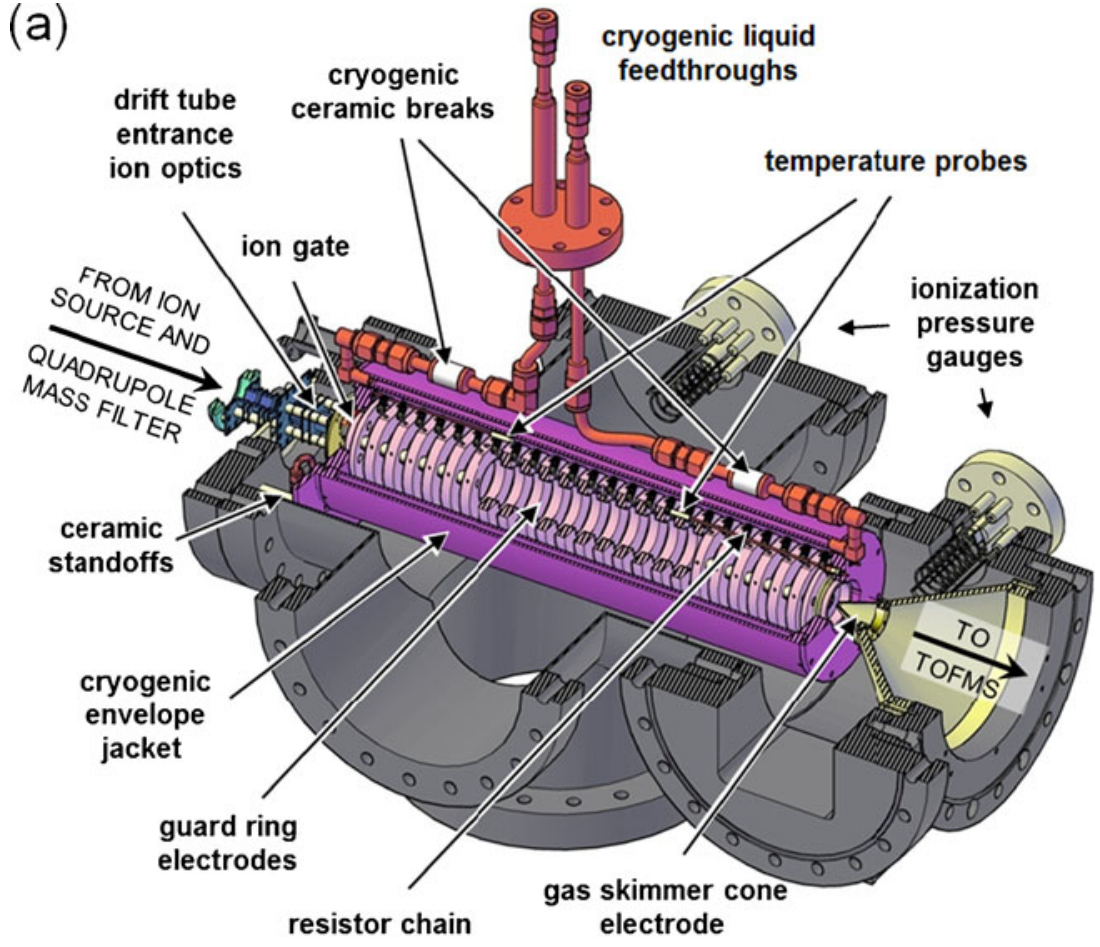

(b)

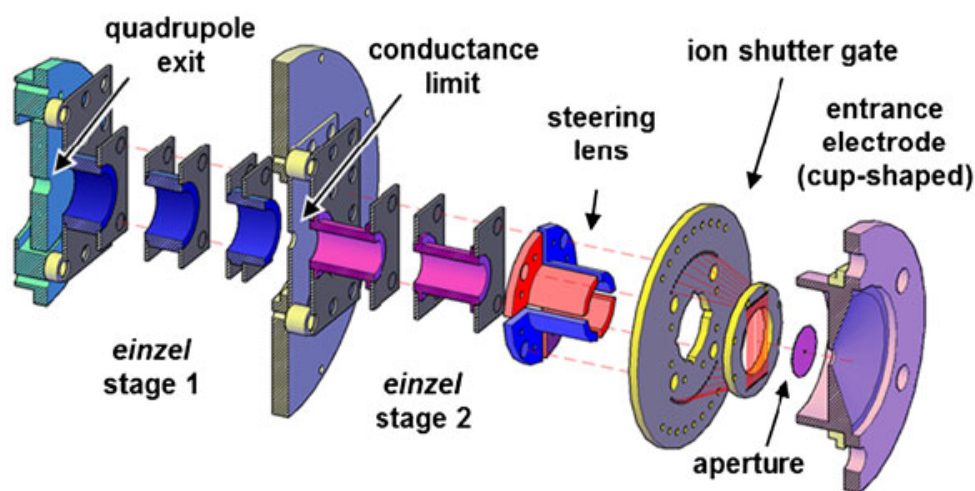

(c)

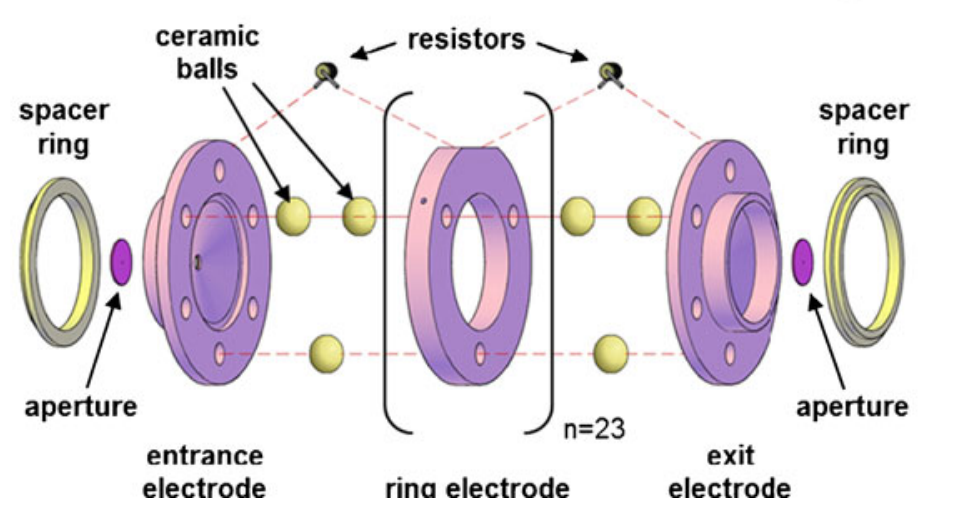

Figure 3. Schematic details of the (a) cryogenic drift tube spectrometer, (b) ion optics between the quadrupole and the drift tube, and (c) drift ring electrode assembly. Note that the latter schematics are exploded views and so distances between ion optical elements are not to scale

Redding, CA). The front aperture is $600 \mu \mathrm{m}$ and the back aperture is slightly larger at $800 \mu \mathrm{m}$, which increases collection efficiency of radially diffuse ions. These values represent a compromise between ion transmission and gas pumping capacity of the vacuum. The drift tube entrance and exit electrodes are beveled on the back-sides to maintain a thin-plate orifice design required for non-turbulent flow. The replaceable apertures used in this work are ca. $0.5 \mathrm{~mm}$ thick. 
The total drift length as measured from front to back aperture is $30.2 \mathrm{~cm}$ at room temperature.

The thermal jacket surrounding the drift tube consists of two parts: a cryogenic Dewar chamber and a resistively heated wrapping. The cryogenic envelope is fabricated by inserting one stainless steel tube into another and welding the ends closed with ring end-caps, creating a closed hollow cavity in the annular region. Fluid feed-throughs are welded at both top ends of the envelope to introduce cryogens on one side while allowing gas displacement and pressure boil-off at the opposite end. The cryogenic flow system is also equipped with pressure relief valves to prevent over-pressurizing as a result of condensed solid constriction of the line. Low drift tube temperatures are maintained by filling the annular region with liquid nitrogen. Alternately the drift tube temperature can be varied in the region between ca. 80 and $300 \mathrm{~K}$ by maintaining liquid nitrogen in the chamber while passing current through resistive tape wrapped around the tube (HTS/Amptek Co., Stafford, TX). Temperatures greater than $300 \mathrm{~K}$ can be accessed by heating the chamber without cryogen present.

The drift ring stack is inserted into the thermal envelope and compressed using stainless steel end-cap flanges. A vacuum seal is created by compressing silver wire between stainless steel components. Utilizing silver wire allows for higher temperatures to be accessed as opposed to using more conventional indium wire seals. Ceramic ring spacers are used between the chamber end-caps and electrodes to facilitate electrical isolation (Figure $3 b$ ).

The drift tube pressure is controlled manually by a precision variable leak valve (model 203; Granville-Phillips, Longmont, CO). Pressure is monitored by a capacitance diaphragm gauge (Inficon, East Syracuse, NY) mounted to the gas manifold external to the drift tube. Because of thermal transpiration effects, the pressure measured by the manometer will be significantly different than the actual pressure in the drift tube, and so the manometer reading must be calibrated. A suitable calibration relationship between the actual and measured pressure values can be generated by measuring the drift time of an ion of known mobility across the range of operational conditions used. We use the krypton cation $\left(\mathrm{K}_{0}=18.6 \mathrm{~cm}^{2} \mathrm{~V}^{-1} \mathrm{~s}^{-1}\right)$ for pressure calibration as it is straightforward to introduce to the instrument and possesses a mobility value which remains constant across a wide range of $\mathrm{E} / \mathrm{N}$ [41]. The drift time measurement of an ion with a known $K_{0}$ value can be used to find the actual pressure of the drift tube by using the relationships in Eqs. 1 and 2. To determine the ion drift time accurately, the measured drift time must be corrected for the time the ion spends outside of the drift tube, i.e., in the region between the drift tube exit and the time-of-flight MS. The time correction is determined by plotting the measured arrival time of an ion to the inverse of the drift voltage and extrapolating the time to zero field in a procedure described previously [28]. This calibration procedure is repeated for a range of masses in order to account for the mass-dependent time-of-flight.
The drift tube temperature is monitored with two redundant platinum wire wound resistive temperature probes (PT-100 ceramic encased; Omega Engineering, Stamford, CT) inserted at either end of the drift chamber ca. $6 \mathrm{~cm}$ from the ends and suspended directly into the drift gas atmosphere. To take advantage of cryogenic purification of the drift gas, the gas line is passed through the lower annular region of the envelope prior to being introduced into the drift tube. Thermal contraction can lead to significant problems associated with alignment and this issue was addressed by Bowers and coworkers by supporting an all-copper drift ring and chamber assembly on ceramic alignment rods [27]. In this work, the drift ring assembly is fabricated with stainless steel (alloy 304) and aligned with ceramic (alumina) ball spacers compressed on either end. While stainless steel has rather poor thermal conductive properties, it possesses excellent temperature stability, allowing the temperature to be changed, equilibrated and experiments to be run within a reasonably long time window. The entire drift tube assembly is mounted onto a single flange using ceramic standoffs and inserted into a high vacuum chamber. This allows the drift tube assembly to be insulated by vacuum, resulting in excellent thermal isolation without condensation and ice buildup problems as would be the case with exposing the assembly to air. The single flange mounting is important to allow the drift tube assembly to freely expand and contract during thermal cycling. Isolation of the drift tube envelope also allows more experimental flexibility with regards to operational voltage. The drift chamber is electrically biased at a voltage that is between that of the first and last drift electrodes to minimize voltage differences which would otherwise initiate gaseous electrical breakdown. The same strategy was utilized by Jarrold and coworkers for their high resolution drift tube [15], except in their work, the chamber was physically connected to the middle drift ring whereas here the chamber voltage is supplied by an independent power supply. The only advantage to the latter strategy is experimental versatility: we utilize the chamber voltage supply to intentionally initiate gaseous electrical breakdown in order to create a high flux of ions for tuning purposes. Under routine operation, electrical breakdown is a particularly significant issue to address when using helium drift gas, as the breakdown threshold for helium is 150 200 V DC at the Paschen minimum.

\section{Time-of-Flight Mass Analyzer}

A skimmer cone positioned at the ion exit of the drift tube defines the ion energy entering the TOF, which is typically 20 $30 \mathrm{eV}$ laboratory frame for proper detector coincidence of ions to the TOF detector (dual chevron stacked $25 \mathrm{~mm}$ microchannel plates; Burle Electro-Optics, Sturbridge, MA). A fivestage ion optical assembly collimates and shapes the ion beam for introduction into the ion extraction source of the orthogonal TOF. It is important to define the ion beam into a narrow distribution of both kinetic energy and space for adequate 
performance of the orthogonal TOF $[7,49]$. Because the ions exiting the drift tube are near or below thermal due to collisional cooling, they are readily focused into a tightly collimated ion beam. A small but noticeable improvement in the TOF mass resolving power is observed for low temperature drift tube operation. The small linear TOF used for this instrument is constructed in-house and has a path length of $29.3 \mathrm{~cm}$ and can achieve a mass resolving power of ca. 200, which is suitable for small molecule ions generated by electron ionization. This relatively short TOF disperses ions in a time window of ca. $5 \mu \mathrm{s}$, and the TOF can be operated at an acquisition frequency approaching $100 \mathrm{kHz}$ with reduced $\mathrm{m} / \mathrm{z}$ range. This high acquisition rate allows proper time bin sampling of ion distributions from the IM and is important for obtaining good counting statistics on ions of low abundance. Maximum frequency operation of the TOFMS is limited by electronic noise imposed by the rise and fall of the pulser, which must be attenuated with appropriate acquisition time delays before and after each mass dispersion event.

Simultaneous ion mobility and mass spectral data are acquired using an interleaving technique where TOF acquisition pulses are systematically offset across the drift time window to sample the complete mobility space [50]. Commercially available custom hardware and software are used for the two-dimensional (2-D) data acquisition and visualization (TDCx8 system; Ionwerks, Inc., Houston, TX). A custom-written LabVIEW interface (National Instruments Co., Austin, TX) was developed to control and monitor instrument power supplies.

\section{Results and Discussion}

A series of room temperature experiments were conducted in order to characterize the ion injection potentials for small mass ions. One critical aspect of ion mobility measurements on small mass ions is the energy threshold associated with ion activation in the presence of ion-neutral collisions. Field strengths in the elevated pressure regimes of ion traversal must be kept to a minimum to prevent collisional activation, which can lead to structural rearrangement, collisional ion dissociation and/or endothermic ion reaction chemistry with impurities in the drift gas. On the other hand, higher injection energies lead to higher ion transmission which improves instrument sensitivity and thus it is desirable to determine the highest voltage that leads to no measurable change in the nature of the ions being studied.

To characterize the limits for ion injection into the drift tube, a mixture of benzene vapor in krypton gas was ionized using EI and analyzed by the IM-MS instrument. Benzene $\left(\mathrm{C}_{6} \mathrm{H}_{6}, \mathrm{~m} / z\right.$ 78) and krypton $(\mathrm{m} / z \mathrm{84})$ have similar nominal $\mathrm{m} / \mathrm{z}$ values, but distinctly different chemical characteristics, which is expected to give rise to a close spacing in the mass spectrum and a clear peak separation in the mobility spectrum. Additionally, the benzene radical cation will dissociate into fragment ions when activated whereas the krypton cation will not, and so a comparison of relative abundances of the benzene and krypton ion peaks will provide some indication of the extent of ion activation that is occurring at various ion injection energies. A high abundance of the benzene molecular ion was achieved using $34 \mathrm{eV}$ electrons for ionization. The resulting 2-D spectrum of this experiment is contained in Figure $4 \mathrm{a}$ with the quadrupole set to transmit all ions generated in the source (radiofrequency only mode). In these 2-D projections, the ion mobility arrival time distribution is projected on the $y$ axis and the mass is plotted on the x-axis. One result of this manner of data projection is the observance of a trend line in the mobility-mass analysis that relates to the chemical species-dependent scaling of ion mobility to ion mass. Such trend lines are one novel aspect of the IM-MS analysis, as they are specific to the chemical composition of the analyte ion, and can be used for ion characterization purposes [51]. For example, in Figure 4a, a line is drawn across ions which are identified as hydrocarbon species generated from fragmentation of benzene. The other ion species $\left(\mathrm{Kr}^{+}\right.$and $\mathrm{Kr}^{2+}$ ) clearly deviate from this line. Note also that the benzene molecular ion signal $(\mathrm{m} / \mathrm{z} 78)$ is shifted slightly to higher mobility (faster drift time) with respect to the hydrocarbon fragment ion trend, which is a result of the ordered ring structure of benzene. The close correlation in mobility of the $\mathrm{Kr}^{+}$and $\mathrm{Kr}^{2+}$ species is confirmed by previously published mobility data in helium [42], and this measurement is used to verify the instrument calibration. Figure $4 \mathrm{~b}$ contains a series of mass-selected spectra corresponding to decreasing ion injection energy. Here, the quadrupole is set to transmit a relatively wide $\mathrm{m} / \mathrm{z}$ window centered at ca. $m / z$ 80. Fragmentation of the benzene molecular ion is observed at injection energies at and above $20 \mathrm{eV}$ laboratory frame. In addition, an overlay of the massselected spectra taken at three injection energies $(10,30$, and $50 \mathrm{eV}$, Figure 4c) reveals a small but measurable shift in ion drift times, which arises from deeper penetration of ions into the drift tube prior to reaching a constant drift velocity (i.e., a decrease in the effective drift length). This ion penetration effect was also noted by Kemper and Bowers and identified as a source of error in determining the distance of ion drift [28]. In this work, ion penetration accounts for less than ca. $1 \%$ of the total drift length and is not measurable at injection potentials below $20 \mathrm{eV}$. The experimental results for the benzene/krypton mixture suggest that ion injection energies above ca. $20 \mathrm{eV}$ should be avoided for the study of small ions less than ca. $100 \mathrm{~m} / z$. The use of low fields to inject ions into the drift tube negatively impacts ion transmission owing to collisional scattering of ion. It was estimated that over $99 \%$ of ions formed in the ion source are lost prior to detection in the TOF, mostly due to losses incurred at ion injection and drift region traversal. This is a necessary compromise to maintaining low ion temperatures, which would otherwise perturb the mobility and mass measurements due to fragmentation and/or ion chemistry.

A series of variable temperature experiments were conducted to explore the separation performance of the 
(a)

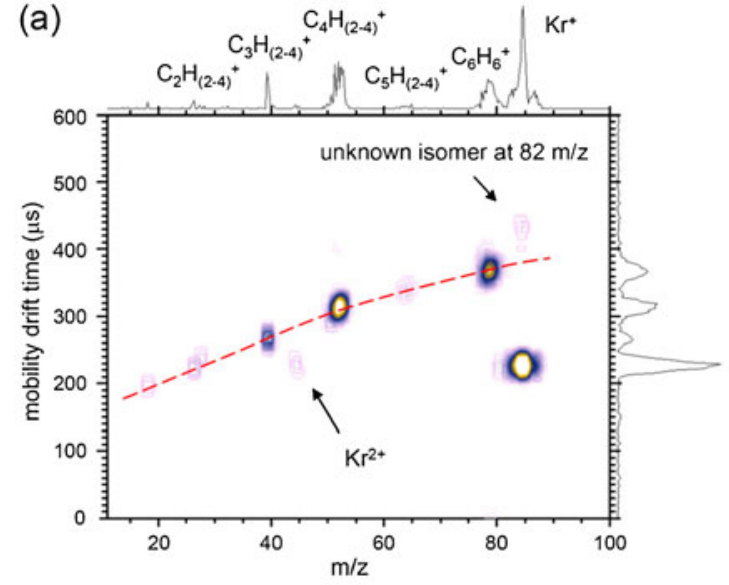

(c)

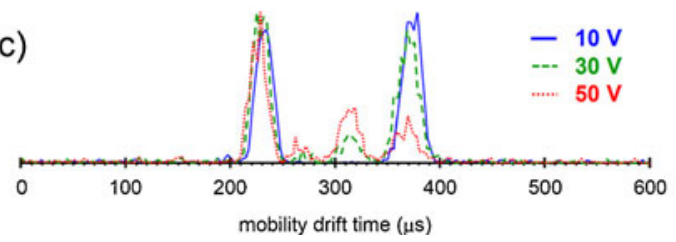

(b)

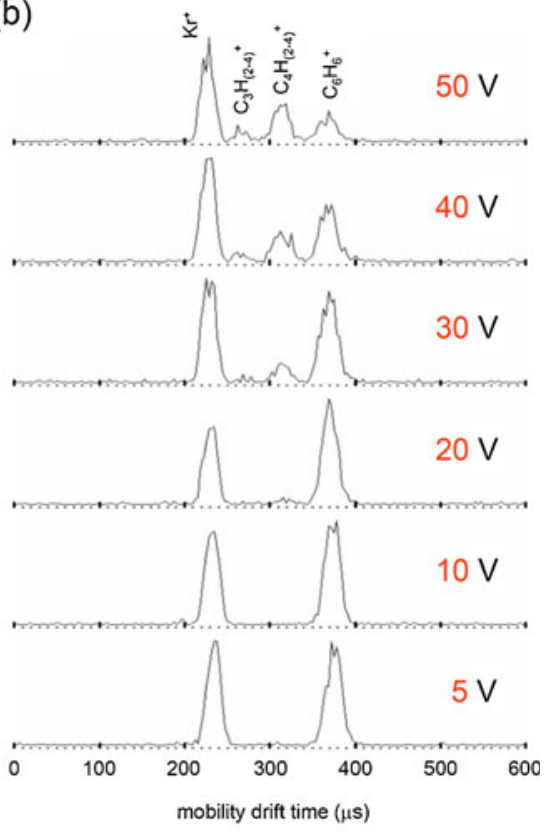

Figure 4. (a) A 2-D ion mobility-mass spectrum of a krypton/benzene mixture ionized with $34 \mathrm{eV}$ electrons. The quadrupole is set to pass all ions generated in the source, including fragments. The relative signal intensity contour plot displays a correlation between the mobility and mass related to the ion's chemical class, in this case linear chain hydrocarbons. A dotted line is drawn to guide the eye. (b) lon mobility arrival time spectra taken at decreasing ion injection energies (lab frame) into the drift tube with the quadrupole set to only pass ions in a wide $\mathrm{m} / \mathrm{z}$ window centered at ca. 80. (c) A composite of three mass-selected mobility spectra taken at 10, 30, and $50 \mathrm{eV}$ ion injection, illustrating a slight shift in arrival time for ion distributions as the injection energy is increased above $30 \mathrm{eV}$. Experimental conditions are as follows: $10 \mu \mathrm{s}$ ion gate width, $7.5 \mathrm{~V} \mathrm{~cm}^{-1}$ electric field across the drift tube supporting 1.5 Torr of helium gas at $298 \mathrm{~K}$

(VT) IM. In these experiments the ions were detected by an on-axis continuous dynode detector (refer to Figure 1) and no special consideration was given for minimizing the ion injection energy, which is ca. $50 \mathrm{eV}$ in these studies. Ionization of benzene with ca. $120 \mathrm{eV}$ electrons generates the $\mathrm{C}_{6} \mathrm{H}_{6}$ radical cation and a number of lower $\mathrm{m} / \mathrm{z}$ fragment ions. The identity of the mobility separated ions for electron ionized benzene is given in the previous section (refer to Figure 4). The field strength was varied across the same range for two temperatures and the resulting resolution of the benzene fragments was observed. Corresponding $\mathrm{E} / \mathrm{N}$ values (in Townsend units, $\mathrm{Td}$ [52]) are provided in Figure 5. These experiments correspond to a drift voltage variation between 200 and $700 \mathrm{~V}$ at a constant pressure of 1 Torr helium. With the drift tube maintained at room temperature $(300 \mathrm{~K}$, Figure $5 \mathrm{a})$, the ion fragments from benzene all appear as a single, broad arrival time distribution at low electric field strengths $\left(7 \mathrm{~V} \mathrm{~cm}^{-1}\right.$ Torr $\left.^{-1}\right)$. As the electric field is raised, the distribution narrows and eventually reveals a second distribution at $17 \mathrm{~V} \mathrm{~cm}^{-1} \mathrm{Torr}^{-1}$. At field strengths greater than $17 \mathrm{~V} \mathrm{~cm}^{-1} \mathrm{Torr}^{-1}$, the distribution broadens and a loss of ion mobility resolution is observed. The same field experiment conducted at cryogenic $(80 \mathrm{~K})$ drift gas temperatures does not exhibit a loss in resolution as the field is increased, whereas at the lowest field strength $\left(7 \mathrm{~V} \mathrm{~cm}^{-1}\right.$ Torr $^{-1}$ ), two peaks are resolved similar to the best case observed at room temperature. At higher fields, the peak resolution continues to improve and three distinct ion distributions are baseline resolved at the highest field investigated $\left(23 \mathrm{~V} \mathrm{~cm}^{-1} \mathrm{Torr}^{-1}\right)$. The change in ion mobility resolution with increasing voltage has been noted previously $[53,54]$. Hill and coworkers have combined several experimental parameters into an analytical expression for conditional ion mobility resolving power which predicts that the optimum resolution would be voltage-dependent and change with respect to the drift gas temperature [55]. A plot of the theoretical and experimental IM resolving powers observed in this study for both temperatures is provided in the Supplementary Material Section (which can be found in the electronic version of this article). The conditional resolving power is calculated from methods described previously [55] using the experimental reduced mobility value of the benzene cation $\left(\mathrm{K}_{0}=11.4 \mathrm{~cm}^{2} \mathrm{~V}^{-1} \mathrm{~s}^{-1}\right.$ [56] $)$ and the experimental ion gate width of $3 \mu \mathrm{s}$. The diffusionlimited resolving power is calculated from $\mathrm{Eq} 3$. The experimentally measured resolving power values follow the general trend of the predicted conditional resolving power, but consistently fall below theoretical values by about $50 \%$ at room temperature and ca. $70 \%$ at $80 \mathrm{~K}$. This indicates that the instrument is not performing at high separation efficiency. Lower than theoretical values for resolving power are expected for analytical IM spectrometers and it should be noted that the theory does not account for effects such as space charge and detector circuit response, both of which we 
(a)

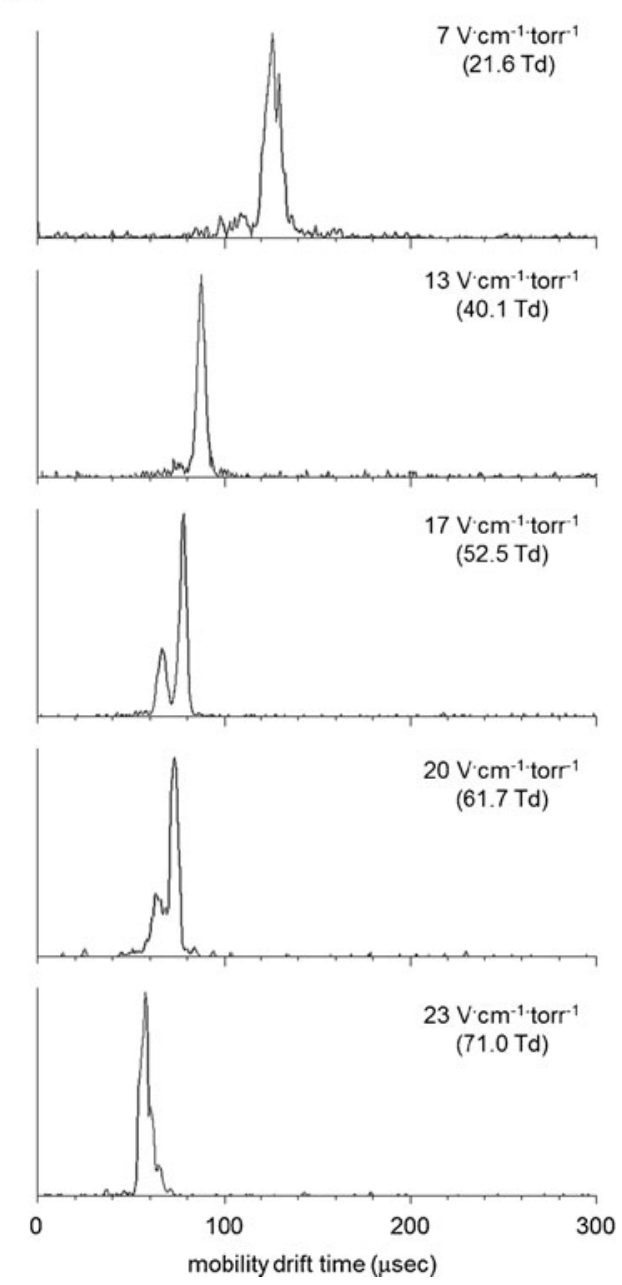

(b)

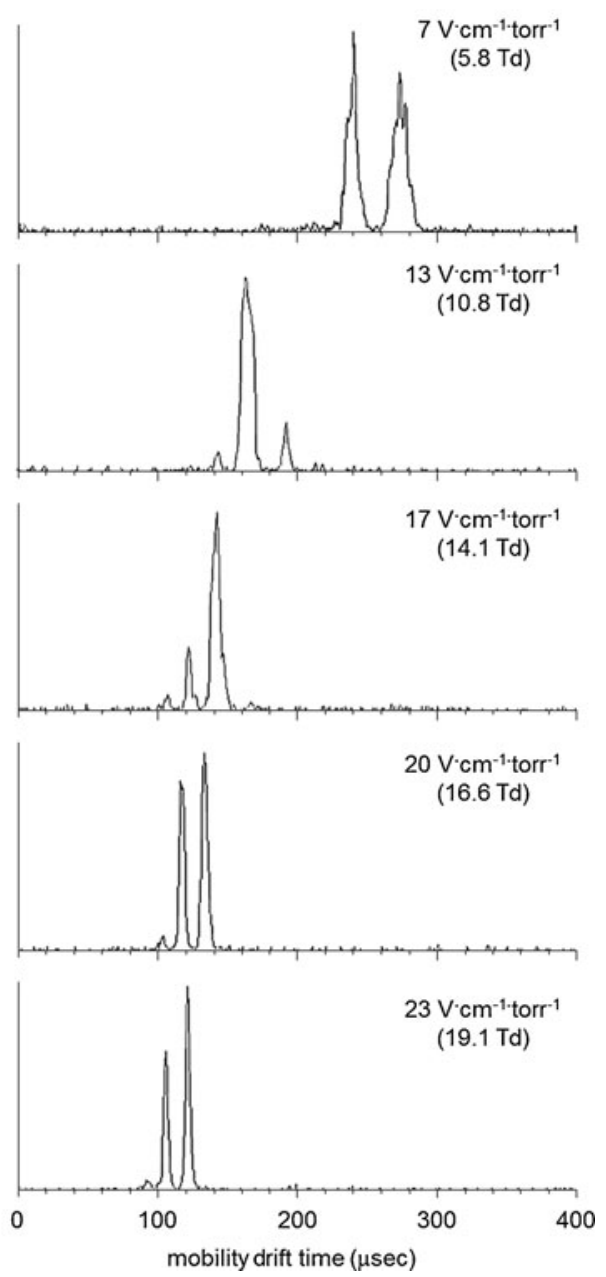

Figure 5. Ion mobility spectra of fragment ions generated from the ionization of benzene with ca. $120 \mathrm{eV}$ electrons taken at two gas temperatures. (a) At room temperature, resolution of two fragment ion peaks is optimal at $17 \mathrm{~V} \mathrm{~cm}^{-1}$. Torr ${ }^{-1}$ and degrades at higher field strengths. (b) At $80 \mathrm{~K}$, three peaks are resolved at the highest field strength examined $\left(23 \mathrm{~V} \mathrm{~cm}^{-1} \mathrm{Torr}^{-1}\right)$. For each temperature, the electric field is increased from 7 to $23 \mathrm{~V} \mathrm{~cm}^{-1} \mathrm{Torr}^{-1}$, top to bottom and helium drift gas is used in all experiments. Corresponding E/N values (in Townsend units, Td) are also provided for each spectrum

speculate are primary contributing factors in the decreased separation efficiency observed. The inline continuous dynode detector used to acquire the spectra in Figure 5 is approximately an order of magnitude slower in temporal response than the microchannel plate and discrete dynode detectors used in fast time-of-flight experiments which operate on the sub-nanosecond timescale. Additional signal broadening results from improperly impedance-matching the detection circuit, which was originally developed in-house for TOF ion counting whereby the ion fluxes are lower than what are being monitored in this application. It should also be noted that the spectra were obtained at relatively high injection voltages which result in higher ion transmission into the drift tube, and so space charge broadening is certainly a possibility. These spectra were obtained in the initial testing phases of the instrument prior to operating under optimized conditions with an operational MS, and it is expected that resolving power values will continue to improve over time. In general, we observe a drastic improvement in the ion mobility resolution with combinations of low gas temperature and increased electric field. The notable exceptions to this trend are the ions of polar species, such as carbon dioxide and water, which changed considerably with changes in the gas temperature, and this behavior is expected owing to strong ion-neutral interaction potentials [57].

Equation 3 only considers the effect of temperature on resolution for hard-sphere (elastic) ion-neutral collisions. At very low temperatures such as those examined in this work the average velocity of the neutral gas is significantly reduced, leading to an enhanced contribution to inelastic ion-neutral interactions. For example, in earlier work we showed that distinct forms of a variety of isomeric radical cations, viz. distonic and conventional forms of the methanol radical cation as well as the keto- and enol forms of acetone radical cations, can be separated at reduced temperatures 
[57]. Another important separation of isomeric ions by IM is the separation of electronic states of transition metal ions. Energetic ionization of transition metals often results in formation of long-lived electronically excited species. Oftentimes these long-lived excited metal ions have distinctly different electron configurations from that of the ground state ion, i.e., higher energy $d$-orbitals in which the $d$ to $p$ orbital relaxation of the electron is spin forbidden [58]. Thus, these excited state ions are metastable within the temporal resolution of the ion mobility experiment and can be directly observed due to the large mobility difference between ground and excited state ions [28]. We have investigated one such transition metal, the $\mathrm{Ti}^{+}$cation, using the (VT) IM-MS instrument. The $\mathrm{Ti}^{+}$cation is formed by EI of the volatile compound $\mathrm{TiCl}_{4}$, which can be introduced directly into the ionization source of the instrument. At room temperature, the 2-D mobility-mass plot contains numerous ion signals corresponding to hydrated ion species resulting from ion-neutral reactions with trace levels of water in the drift gas (data not shown). Below the freezing point of water $(273 \mathrm{~K})$, the abundances of the hydrated ions are diminished, which indicates that the residual water is condensed out of the drift gas. Figure 6a contains the 2-D mobility-mass spectrum of ionized $\mathrm{TiCl}_{4}$ obtained at $121 \mathrm{~K}$. Here, the injection energy is maintained at $15 \mathrm{eV}$ to minimize collisional quenching of metastable ions. Note that in Figure $6 \mathrm{a}$ the $\mathrm{Ti}^{+}$ion and a complete series of metal halide ions $\left(\mathrm{TiCl}_{n}, n=1-4\right)$ are observed. Note also that the $\mathrm{Ti}^{+}$ion signal is comprised of two clearly resolved ion populations in the mobility dimension with a third distribution appearing as a partial shoulder at ca. $500 \mu \mathrm{s}$ on the more abundant ion signal. A previous IM-MS investigation of the $\mathrm{Ti}^{+}$cation also revealed as many as three mass-isobaric ion populations in the mobility analysis [28]. In this previous work and in the experiments reported here, the lower mobility ion populations are identified as the excited state $\mathrm{Ti}^{+}$cation based on appearance energy measurements. In addition to these features, the IM-MS spectrum of $\mathrm{TiCl}_{4}$ also contains an ion signal at $m / z 64$, which is uncorrelated in the mobility analysis. Mass selection of the metal cation $(\mathrm{m} / \mathrm{z} 48)$ reveals that the ion signal at $\mathrm{m} / z$ 64 is a product ion, identified as $\mathrm{TiO}^{+}$(Figure 6b). This ion assignment is based on both the measured $\mathrm{m} / \mathrm{z}$ as well as previously reported gas phase reactivity of $\mathrm{Ti}^{+}$to preferentially form $\mathrm{TiO}^{+}[59,60]$. The "streaking" of the $\mathrm{TiO}^{+}$ion signal results from this product ion forming during transit of the precursor $\mathrm{Ti}^{+}$species through the drift tube, and this behavior has been observed in other ion mobility studies of reactive metal ion systems [61]. It appears that the reactant neutral species is residual water, which remains present in the drift gas even at low temperature; however, it is possible that the product ion arises from reaction of $\mathrm{Ti}^{+}$with residual $\mathrm{O}_{2}$. The instrument utilizes ultra-high purity helium (99.999\%), which passes through a hydrocarbon and water filter column and then through the bottom of the liquid nitrogen envelope before being introduced into the drift chamber. While the percent
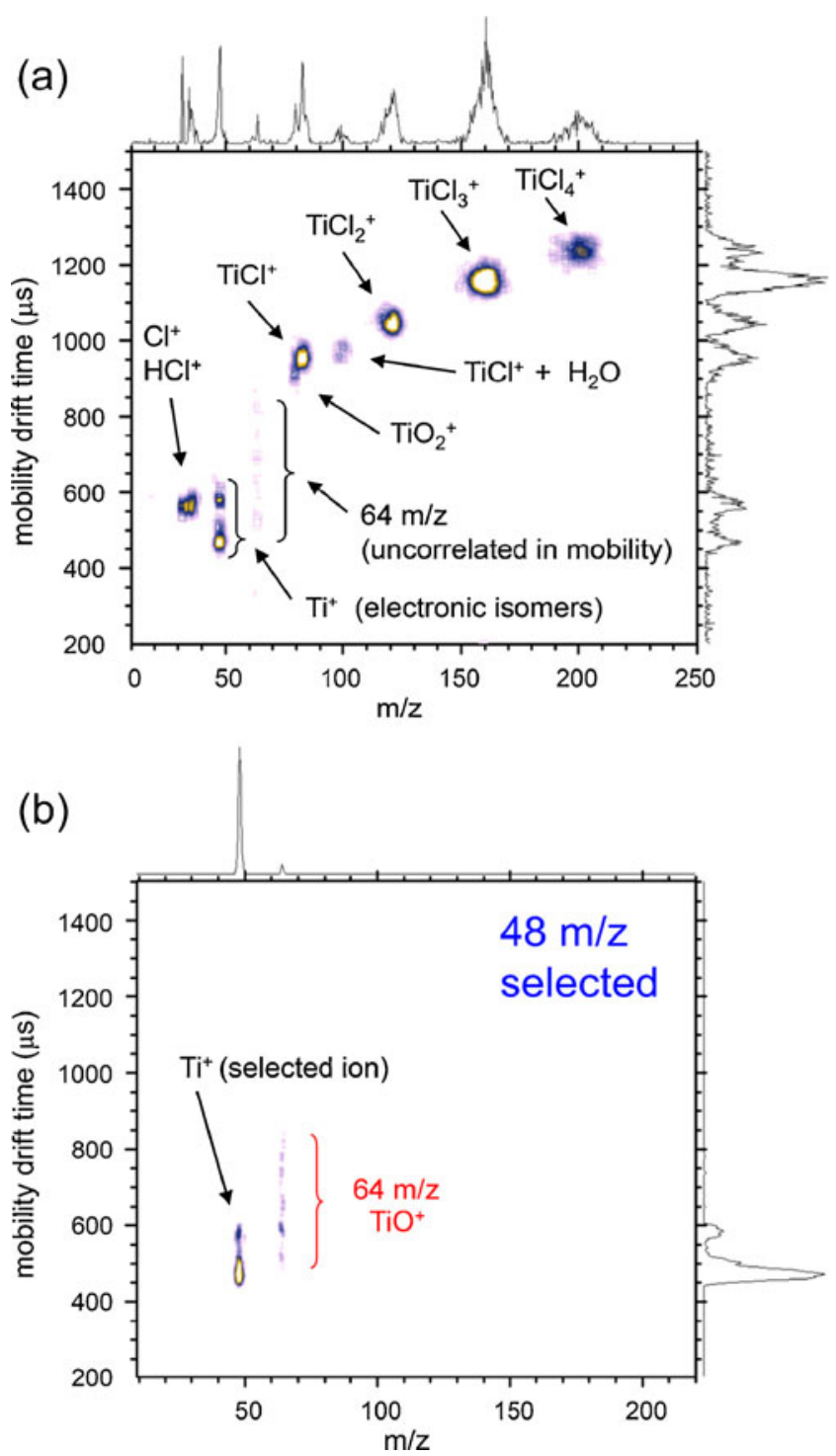

Figure 6. (a) Ion mobility-mass spectrum of titanium chloride ionized at $70 \mathrm{eV}$. The helium drift gas temperature is $121 \mathrm{~K}$. The titanium cation exhibits two baseline resolved ion populations and a partial third feature manifesting as a shoulder on the higher mobility distribution. The lower mobility ion signals are identified as excited state ions based on appearance energy experiments (not shown). (b) Mass selection of the titanium cation prior to IM-MS analysis results in the appearance of the $\mathrm{Ti}^{+}$cation as well as the uncorrelated ion signal at $64 \mathrm{~m} / z$ which is identified as $\mathrm{TiO}^{+}$

impurity present in the drift chamber is assumed to be low, even a very small amount of impurity can be problematic for sufficiently endothermic reactions to occur, such as the case with the highly reactive $\mathrm{Ti}^{+}$cation [62]. Finally, in the data contained in Figure 6, it appears that electronic state-specific reaction chemistry is occurring in this system. That is, the $\mathrm{TiO}^{+}$ion signal appears at the same apparent mobility as that of the $\mathrm{Ti}^{+}$excited state ions, which suggest that the product ion is formed by reaction of the excited state ions. Metal excited states are well-known to be more reactive than are 
ground state ions [58]. Further experiments with the titanium and other metal ion systems are currently underway.

\section{Conclusions}

The design considerations and initial performance of a variable temperature drift tube spectrometer are presented. Integral to the success of conducting these small ion studies through multiple stages of pressure is the use of high speed ion gating (up to $5 \mathrm{kHz}$ ) and mass analysis (up to $100 \mathrm{kHz}$ ) which compensates for the inherent low ion transmission of uniform field drift cells with conductance limiting exit apertures. One consequence of injected ion experiments is ion heating during transfer from vacuum to elevated pressure, which is characterized here using a benzene/ krypton mixture. Experimental results demonstrate depletion of the benzene molecular ion signal at injection voltages of ca. $20 \mathrm{eV}$ laboratory frame and above. Low energy ion injection is preferred if ion fragmentation is to be avoided, however, the utility of collisional activation experiments should be noted as well. Particularly, ion activation after initial mass analysis but prior to IM-MS analysis (e.g., MS/ IM-MS) is advantageous for interrogating the fragmentation pattern of a single $\mathrm{m} / \mathrm{z}$ with combined IM-MS analysis. Insource EI fragmentation of benzene was also investigated with IM. The benzene fragment ion results obtained at room temperature and $80 \mathrm{~K}$, demonstrates the added benefit of improving the resolution of the mobility experiment using low temperature. The observed shifting of the optimal resolution voltage to higher values at lower temperatures is predicted by theory, and experimental values correlate to the general trends, though underperform theoretical resolving power expectations by $50 \%$ or more and depended largely on the operational temperature. The preliminary results with the $\mathrm{TiCl}_{4}$ system is promising and illustrates several important points regarding the (VT)IM experiment including the advantages of selected ion capabilities for unambiguous spectral interpretation and the importance of minimizing the extent of drift gas impurities (e.g., high purity gases and reduced pressure IM).

To date, we have investigated a number of other chemical systems and in all cases, the ion mobility separation benefits from a reduction in the drift gas temperature. We will address specific analytical improvements made by the low temperature ion mobility technique in a future report. This work represents a preliminary characterization of an instrument designed for larger mass ion studies. A number of other ionization sources (e.g., chemical, electrospray and laser ionization) and instrument operational modes (e.g., ion trap and transfer, multiple ion gate modes and multiplexed data acquisition) have been developed and will be discussed in future manuscripts. Of particular interest are the capabilities of (VT)IM-MS for the study of large ions, such as inorganic clusters and biomolecules where the high resolving power of the instrument will be advantageous. Additionally, VT studies will provide further insight into the nature and thermodynamic stability of gas-phase ion structure.

\section{Acknowledgments}

The authors are grateful for the technical expertise of Greg Matthijetz, who designed and fabricated much of the electronics and computer control hardware utilized on the instrumentation. The authors also acknowledge Ionwerks, Inc. of Houston, TX and, in particular, Tom Egan for assistance in customizing the data acquisition system for the high speeds necessary to acquire low $\mathrm{m} / \mathrm{z}$ ion data. This work was supported by the National Science Foundation (DBI-0821700).

\section{References}

1. McKnight, L.G., McAfee, K.B., Sipler, D.P.: Low-Field Drift Velocities and Reactions of Nitrogen Ions in Nitrogen. Phys. Rev. 164, 62 (1967)

2. Young, C.E., Edelson, D., Alconer, W.E.: Water Cluster Ions: Rates of Formation and Decomposition of Hydrates of the Hydronium Ion. J. Chem. Phys. 53, 4295-4302 (1970)

3. Bowers, M. T., Kemper P. R., von Helden, G., van Koppen, P. A. M.: Gas-Phase Ion Chromatography: Transition Metal State Selection and Carbon Cluster Formation. Science. 260, 1446-1451 (1993)

4. Jarrold, M.F.: Drift Tube Studies of Atomic Clusters. J. Phys. Chem. 99, 11-21 (1995)

5. Jarrold, M.F.: Peptides and Proteins in the Vapor Phase. Ann. Rev. Phys. Chem. 51, 179-207 (2000)

6. Clemmer, D.E., Hudgins, R.R., Jarrold, M.F.: Naked Protein Conformations: Cytochrome $c$ in the Gas Phase. J. Am. Chem. Soc. 117, 10141-10142 (1995)

7. Guilhaus, M., Selby, D., Mlynski, V.: Orthogonal Acceleration Timeof-Flight Mass Spectrometry. Mass Spectrom. Rev. 19, 65-107 (2000)

8. Covey, T.R., Thomson, B.A., Schneider, B.B.: Atmospheric Pressure Ion Sources. Mass Spectrom. Rev. 28, 870-897 (2009)

9. Gillig, K.J., Ruotolo, B.T., Stone, E.G., Russell, D.H.: An Electrostatic Focusing Ion Guide for Ion Mobility-Mass Spectrometry. Int. J. Mass Spectrom. 239, 43-49 (2004)

10. Tang, K., Shvartsburg, A.A., Lee, H.N., Prior, D.C., Buschbach, M.A., Li, F., Tolmachev, A.V., Anderson, G.A., Smith, R.D.: High-Sensitivity Ion Mobility Spectrometry/Mass Spectrometry Using Electrodynamic Ion Funnel Interfaces. Anal. Chem. 77, 3330-3339 (2005)

11. Loboda, A.: Novel Ion Mobility Setup Combined with Collision Cell and Time-of-Flight Mass Spectrometer. J. Am. Soc. Mass Spectrom. 17, 691-699 (2006)

12. Giles, K., Pringle, S. D., Worthington, K. R., Little, D., Wildgoose, J. L., Bateman, R. H.: Applications of a Traveling Wave-Based RadioFrequency-Only Stacked Ring Ion Guide. Rapid Commun. Mass Spectrom. 18, 2401-2414 (2004)

13. Ruotolo, B.T., Giles, K., Campuzano, I., Sandercock, A.M., Bateman, R.H., Robinson, C.V.: Evidence for Macromolecular Protein Rings in the Absence of Bulk Water. Science 310, 1658-1661 (2005)

14. Srebalus, C.A., Li, J., Marshall, W.S., Clemmer, D.E.: Gas-Phase Separations of Electrosprayed Peptide Libraries. Anal. Chem. 71, 39183927 (1999)

15. Dugourd, P., Hudgins, R.R., Clemmer, D.E., Jarrold, M.F.: HighResolution Ion Mobility Measurements. Rev. Sci. Instrum. 68, 11221129 (1997)

16. Phillips, P.: Ionic Velocities in Air at Different Temperatures. Proc. $R$. Soc. London, Ser. A 78, 167-191 (1906)

17. Kovarik, A.F.: The Effect of Changes in the Pressure and Temperature of Gases upon the Mobility of the Negative Ions Produced by Ultraviolet Light. Phys. Rev. (Series I) 30, 415 (1910)

18. Erikson, H.A.: The Mobility of Ions at Different Temperatures and Constant Gas Density. Phys. Rev. 3, 151 (1914)

19. Tyndall, A.M., Starr, L.H., Powell, C.F.: The Mobility of Ions in Air Part IV. Investigations by Two New Methods. Proc. R. Soc. London, Ser. A 121, 172-184 (1928) 
20. Tyndall, A.M., Pearce, A.F.: The Variation of the Mobility of Gaseous Ions with Temperature. I. Positive Ions in their Own Gas. Proc. R. Soc. London Series A Math Phys. Sci 149, 426-434 (1935)

21. Mason, E.A., McDaniel, E.W.: Transport Properties of Ions in Gases. John Wiley and Sons, New York (1988)

22. McDaniel, E.W., Martin, D.W., Barnes, W.S.: Drift Tube-Mass Spectrometer for Studies of Low-Energy Ion-Molecule Reactions. Rev. Sci. Instrum. 33, 2-7 (1962)

23. Bloomfield, C.H., Hasted, J.B.: New Technique for the Study of Ionatom Interchange. Discuss. Faraday Soc. 37, 176-184 (1964)

24. Adams, N.G., Smith, D.: The Elected Ion Flow Tube (SIFT); A Technique for Studying Ion-Neutral Reactions. Int. J. Mass Spectrom. Ion Phys. 21, 349-359 (1976)

25. Federer, W., Ramler, H., Villinger, H., Lindinger, W.: Vibrational Temperature of $\mathrm{O}_{2}{ }^{+}$and $\mathrm{N}_{2}{ }^{+}$Drifting at Elevated $\mathrm{E} / \mathrm{N}$ in Helium. Phys. Rev. Lett. 54, 540 (1985)

26. Jarrold, M.F., Bower, J.E., Creegan, K.: Chemistry of Semiconductor Clusters: A Study of the Reactions of Size Slected $\mathrm{Si}^{+}{ }_{\mathrm{n}}(n=3-24)$ with $\mathrm{C}_{2} \mathrm{H}_{4}$ Using Selected Ion Drift Tube Techniques. J. Chem. Phys. 90, 3615-3628 (1989)

27. Kemper, P.R., Bowers, M.T.: A Hybrid Double-focusing Mass Spectrometer-High-pressure Drift Reaction Cell to Study Thermal Energy Reactions of Mass-selected Ions. J. Am. Soc. Mass Spectrom. 1, 197-207 (1990)

28. Kemper, P.R., Bowers, M.T.: Electronic-State Chromatography: Application to First-Row Transition-Metal Ions. J. Phys. Chem. 95, 5134$5146(1991)$

29. Mesleh, M.F., Hunter, J.M., Shvartsburg, A.A., Schatz, G.C., Jarrold, M.F.: Structural Information from Ion Mobility Measurements: Effects of the Long-Range Potential. J. Phys. Chem. 100, 16082-16086 (1996)

30. Shvartsburg, A.A., Jarrold, M.F.: An Exact Hard-Spheres Scattering Model for the Mobilities of Polyatomic Ions. Chem. Phys. Lett. 216, 86-91 (1996)

31. Wyttenbach, T., von Helden, G., Batka Jr., J.J., Carlat, D., Bowers, M.T.: Effect of the Long-range Potential on Ion Mobility Measurements. J. Am. Soc. Mass Spectrom. 8, 275-282 (1997)

32. von Helden, G., Wyttenbach, T., Bowers, M. T.: Inclusion of a MALDI Ion Source in the Ion Chromatography Technique: Conformational Information on Polymer and Biomolecular Ions. Int. J. Mass Spectrom. Ion Processes 146-147, 349-364 (1995)

33. Mao, Y., Woenckhaus, J., Kolafa, J., Ratner, M.A., Jarrold, M.F.: Thermal Unfolding of Unsolvated Cytochrome $c$ : Experiment and Molecular Dynamics Simulations. J. Am. Chem. Soc. 121, 2712-2721 (1999)

34. Bohringer, H., Arnold, F.: Temperature Dependence of Three-Body Association Reactions from 45 to $400 \mathrm{~K}$. The Reactions $\mathrm{N}_{2}^{+}+2 \mathrm{~N}_{2} \rightarrow$ $\mathrm{N}_{4}^{+}+\mathrm{N}_{2}$ and $\mathrm{O}^{+}{ }_{2}+2 \mathrm{O}_{2} \rightarrow \mathrm{O}^{+}{ }_{4}+\mathrm{O}_{2}$. J. Chem. Phys. 77, 5534-5541 (1982)

35. Kobayashi, N., Kojima, T., Kaneko, Y.: Formation of Helium Cluster Ions ${ }^{4} \mathrm{He}_{\mathrm{n}}(n \leq 15)$ in a Liquid Helium Cooled Drift Tube. J. Phys. Soc. Jpn. 57, 1528-1531 (1988)

36. Tanuma, H., Sakamoto, M., Fujimatsu, H., Kobayashi, N.: Very Low Temperature Drift Tube Mass Spectrometer. Rev. Sci. Instrum. 71, 2019-2024 (2000)

37. Reid Asbury, G., Hill Jr., H.H.: Using Different Drift Gases to Change Separation Factors in Ion Mobility Spectrometry. Anal. Chem. 72, 580 $584(2000)$

38. Dwivedi, P., Wu, C., Matz, L., Clowers, B.H., Siems, W.F., Hill Jr., H. H.: Gas-Phase Chiral Separations by Ion Mobility Spectrometry. Anal. Chem. 78, 8200-8206 (2006)

39. Chanin, L.M., Biondi, M.A.: Temperature Dependence of Ion Mobilities in Helium, Neon, and Argon. Phys. Rev. 106, 473 (1957)

40. Ellis, H.W., Pai, R.Y., McDaniel, E.W., Mason, E.A., Viehland, L.A.: Transport Properties of Gaseous Ions Over a Wide Energy Range. At. Data Nucl. Data Tables 17, 177-210 (1976)
41. Ellis, H.W., McDaniel, E.W., Albritton, D.L., Viehland, L.A., Lin, S.L., Mason, E.A.: Transport Properties of Gaseous Ions Over a Wide Energy Range. Part II. At. Data Nucl. Data Tables 22, 179-217 (1978)

42. Ellis, H.W., Thackston, M.G., McDaniel, E.W., Mason, E.A.: Transport Properties of Gaseous Ions Over a Wide Energy Range. Part III. At. Data Nucl. Data Tables 31, 113-151 (1984)

43. Viehland, L.A., Mason, E.A.: Transport Properties of Gaseous Ions Over a Wide Energy Range. IV. At. Data Nucl. Data Tables. 60, 37-95 (1995)

44. Revercomb, H.E., Mason, E.A.: Theory of Plasma Chromatography/ Gaseous Electrophoresis: A Review. Anal. Chem. 47, 970-983 (1975)

45. Nier, A.O: Mass Spectrometer for Routine Isotope Abundance Measurements. Rev. Sci. Instrum. 11, 212-216 (1940)

46. Fite, W.L.: Spatial Separation of Fringe Fields in Quadrupole Mass Filters. Rev. Sci. Instrum. 47, 326-330 (1976)

47. Bradbury, N.E., Nielsen, R.A.: Absolute Values of the Electron Mobility in Hydrogen. Phys. Rev. 49, 388 (1936)

48. Spangler, G.E.: Space Charge Effects in Ion Mobility Spectrometry. Anal. Chem. 64, 1312-1312 (1992)

49. Krutchinsky, A.N., Chernushevich, I.V., Spicer, V.L., Ens, W., Standing, K. G.: Collisional Damping Interface for an Electrospray Ionization Time-ofFlight Mass Spectrometer. J. Am. Soc. Mass Spectrom. 9, 569-579 (1998)

50. McLean, J. A.; Schultz, J. A.; Woods, A. S. Ion Mobility-Mass Spectrometry for Biological and Structural Mass Spectrometry. In: Cole, R. B., Ed., Electrospray and MALDI Mass Spectrometry: Fundamentals, Instrumentation, Practicabilities, and Biological Applications. John Wiley and Sons: Hoboken, New Jersey 2010, pp. 411-439.

51. McLean, J.A., Ruotolo, B.T., Gillig, K.J., Russell, D.H.: Ion MobilityMass Spectrometry: a New Paradigm for Proteomics. Int. J. Mass Spectrom. 240, 301-315 (2005)

52. Huxley, L.G.H., Crompton, R.W., Elford, M.T.: Use of the Parameter E/N. Br. J. Appl. Phys. 17, 1237-1238 (1966)

53. Rokushika, S., Hatano, H., Baim, M.A., Hill Jr., H.H.: Resolution Measurement for Ion Mobility Spectrometry. Anal. Chem. 57, 19021907 (1985)

54. Watts, P., Wilders, A.: On the Resolution Obtainable in Practical Ion Mobility Systems. Int. J. Mass Spectrom. Ion Processes 112, 179-190 (1992)

55. Kanu, A.B., Gribb, M.M., Hill Jr., H.H.: Predicting Optimal Resolving Power for Ambient Pressure Ion Mobility Spectrometry. Anal. Chem. 80, 6610-6619 (2008)

56. Rusyniak, M., Ibrahim, Y., Alsharaeh, E., Meot-Ner, M., El-Shall, M. S.: Mass-Selected Ion Mobility Studies of the Isomerization of the Benzene Radical Cation and Binding Energy of the Benzene Dimer Cation. Separation of Isomeric Ions by Dimer Formation. J. Phys. Chem. A 107, 7656-7666 (2003)

57. Verbeck, G.F., Gillig, K.J., Russell, D.H.: Variable-Temperature Ion Mobility Time-of-Flight Mass Spectrometry Studies of Electronic Isomers of $\mathrm{Kr}^{2+}$ and $\mathrm{CH}_{3} \mathrm{OH}^{*+}$ Radical Cations. Eur. J. Mass Spectrom. 9, 579-587 (2003)

58. Armentrout, P.B.: Electronic State-Specific Transition Metal Ion Chemistry. Ann. Rev. Phys. Chem. 41, 313-344 (1990)

59. Herman, J., Foutch, J.D., Davico, G.E.: Gas-Phase Reactivity of Selected Transition Metal Cations with $\mathrm{CO}$ and $\mathrm{CO}_{2}$ and the Formation of Metal Dications Using a Sputter Ion Source. J. Phys. Chem. A 111, 2461-2468 (2007)

60. Guo, B.C., Kerns, K.P., Castleman, A.W.: Studies of Reactions of Small Titanium Oxide Cluster Cations Toward Oxygen at Thermal Energies. Int. J. Mass Spectrom. Ion Processes 117, 129-144 (1992)

61. Taylor, W.S., May, J.C., Lasater, A.S.: Reactions of $\mathrm{Cu}^{+}\left({ }^{1} \mathrm{~S},{ }^{3} \mathrm{D}\right)$ and $\mathrm{Au}^{+}$ $\left({ }^{1} \mathrm{~S},{ }^{3} \mathrm{D}\right)$ with $\mathrm{CH}_{3} \mathrm{Br}$. J. Phys. Chem. A 107, 2209-2215 (2003)

62. Clemmer, D.E., Aristov, N., Armentrout, P.B.: Reactions of Scandium Oxide $\left(\mathrm{ScO}^{+}\right)$, Titanium Oxide $\left(\mathrm{TiO}^{+}\right)$, and Vanadyl $\left(\mathrm{VO}^{+}\right)$with Deuterium: $\mathrm{M}^{+}-\mathrm{OH}$ Bond Energies and Effects of Spin Conservation. J Phys. Chem. 97, 544-552 (1993) 